\title{
The Role of Women in Managing The Community Based-Ecotourism (Case Study: Anja Community Reserve, Madagascar)
}

\author{
Jean Jacques Fanina \\ jean.jacques.fanina-2018@ fisip.unair.ac.id
}

Ankatso, Université d'Antananarivo

\begin{abstract}
Tourism plays an important role in economic development of Madagascar. It is essential to the survival of local communities. In fact, women play a crucial role in the management of their household, involved in different production activities. Unfortunately, they are little considered and usually facing inequitable power in several developing countries like the case of women in Anja community reserve. This study, a qualitative descriptive one, uses a discursive eco-feminism approach based on three main framework conditions that have been designated. The first deals with politics, good governance and the institutional framework. The second is at the level of local power relations and in the management of natural resources. The last would direct access and control of resources and access to markets and socio-economic aspects. This study aims to emphasize the importance of feminism role in community based-ecotourism of Anja Reserve. The results found that 84,6\% women in Anja are still under the dominance of men whereas $15,4 \%$ are self-reliant socially, politically and economically.
\end{abstract}

Keywords: Eco-tourism, Women, Community-based, Women, Anja, Madagascar.

\section{Introduction}

Being isolated over millions of years and home to thousands of flora and fauna species, 90 per cent of which are endemic to the island, Madagascar possesses a unique biodiversity. The community of Anja is one example unveiling such potential. A touristy area, Anja is located in southern Madagascar's Haute Matsiatra region in the province of Fianarantsoa, 400 kilometers south of the country's capital, Antananarivo. It ensures great biodiversity conservation for sustainable natural resource management, a top priority for development meeting the basic needs of a growing population.

However, tourism in Anja is under threat due to anthropogenic pressures. Besides, deforestation and erosion continue to jeopardize the area. There have not been tangible measures from local government to thwart such issues.

Also, there is a huge gap between men and women in [1]. Men consider themselves as the chief of the family whereas women are miserably considered as housewives, taking care of the kids, doing the laundry, cooking, fetching water or even heading to the field helping their husbands. Such inequality remains unresolvable in various aspects, in society, in politics and so forth despite efforts have been undertaken but remain ineffective [2].

Thus, this study brings concrete understanding on a better environmental green economy. So, it is imperative to assess right from the site what exactly exacerbate the conditions that 
women face in bringing in their share into social integration through gender cross-cutting, local or outside assistance projects and gender mainstreaming in all sustainable development goals [3] indicators as potential opportunities for sustainable economic development.

In fact, there have been few researchers focusing of the environmental and sustainable development. Dobson Andrew, 1996 in his book entitled the 'Environmental sustainability: an analysis and typology' stated the concept of green growth emerging in international policy discourse over the last recent years. [4] introduced some conclusions on the political economy of green growth and how likely it is to succeed in increasing the priority given to environmental policy.

The concept of sustainable development, one of the major concepts of the last thirty years, proves this to a certain degree. Sustainable development has made the environment, one of its essential poles to take into account in the logic of production along with the economic and social aspect.

The objective of this study is then to determining gender role in politics, institutional power for a sustainable environmental green economy development.

\section{Methods}

The research took place on early July till late October of 2017. The study occurred in Anja Community Reserve, Madagascar. Data were collected in Anja taking few samples where respondents were asked about their positions since 1996 until 2017.

There were three phases to be considered. The first one was simply a survey conducted twice a week among 75 households choosing participants aged between 25 to 56 years old. Those respondents were merely adults holding whether formal or informal activities while the second phase focuses on random sampling putting in roughly 50 respondents working in farms. The last phase implied respondents directly involved in eco-tourism business of Anja Reserve.

In fact, this is a descriptive qualitative study, with a phenomenological approach which is an attempt to unfold the meaning of a concept faced by several individuals [5]. The approach used is a cross sectional one namely the data collection independent variables and the dependent ones collected at the same time [6].

The research was conducted in Anja carried out during 90 days in hope to get the preliminary research. Observations were conducted at three stages every day, and that is, in the morning at 08.00-09.30, then at noon at 14.00-15.30, and finally at 16.00-17.30. Heavy rain or any weather mishaps were avoided when observation was carried out.

\section{Results}

\subsection{Local Community Perception on the Importance of Female Political Leadership}

Culture has a very important role in the conservation of biodiversity when undertaking the preservation of Anja Reserve. The figure below indicates the perception of local community on the importance of the existence of women leadership in managing Anja 
Reserve. [7] views women participation in politics and in decision making process still imbalanced. Such local perception can be seen in the following figure 1 .

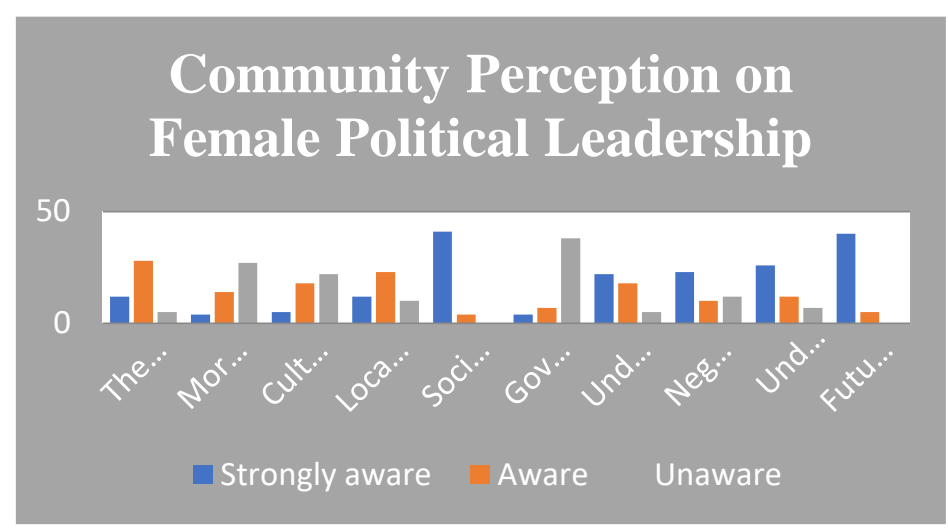

Fig. 1. Community Perception About Female Political Leadership

The results of the figure 1 in superficial seen that in general the villagers of Anja understand and are aware of the importance of female gender role in the management of Anja Reserve. The general manual tendency indicate the variety of used terms on Anja preservation by women hovering $80 \%$ and which hypothesis is well proven as people understand and know the sustainability aspects as analyzed with the use of chi-squared calculation as demonstrated by Balakrishnan et al, 2013 when using the formulation known as chi-squared test. This is a test shortened from Pearson's chi-squared test which a statistic test is measuring the sampling distribution as follow:

$$
\mathrm{X}_{2}=\sum_{i=1}^{r} \frac{(\mathrm{Oi}-\mathrm{Ei}) 2}{\mathrm{Ei}}
$$

Chi-squared value obtained large count of 25,21 . The level of significance $0,05 \mathrm{X} 2$ value is 12.592. If the value of X2 is smaller than of X2 table, it means that the used hypothesis or Ho unacceptable signaling that the public are fully aware of the importance of women leadership in managing Anja Reserve. On the contrary though, if the value of X2 is bigger than of X2 table, it means that the local peoples' awareness regarding the importance of women role in managing the Reserve of Anja has not yet reached the expected level.

\subsection{Number of Men and Women in Managing Anja Reserve}

During our analysis, it was perceived that men still lead far ahead of women in their position at Anja Reserve in all aspects as indicated in the following figure. 


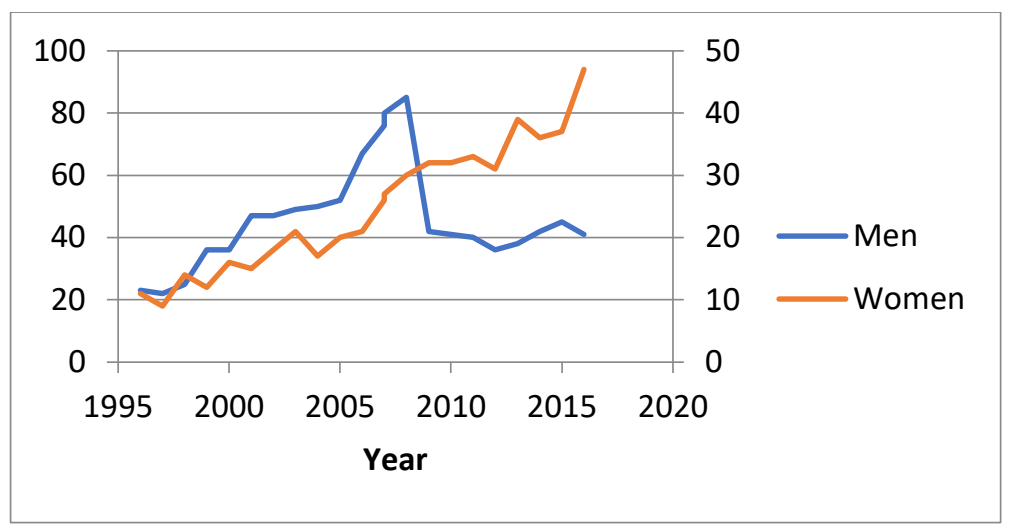

Fig. 2. Number of Men and Women Leadership in Anja Reserve

The figure 2 explains the number of inhabitants, men and women managing the Reserve of Anja. In fact, the most important male dominance is evident in this area. Besides, with regard to the figure above, it is undeniable to assume that during the year 1996 and 2006, women held very few positions which were lower than in 2015 while in 2009 both had severe job loss impacted by the crisis.

\subsection{Socio-Economic Factors of Men and Women in Anja Reserve}

As mentioned in our figure 3 below, it is indicated that some parameters prevail with regard to women in leadership which clearly emphasize the socio-economic factors of those women living in Anja Reserve.

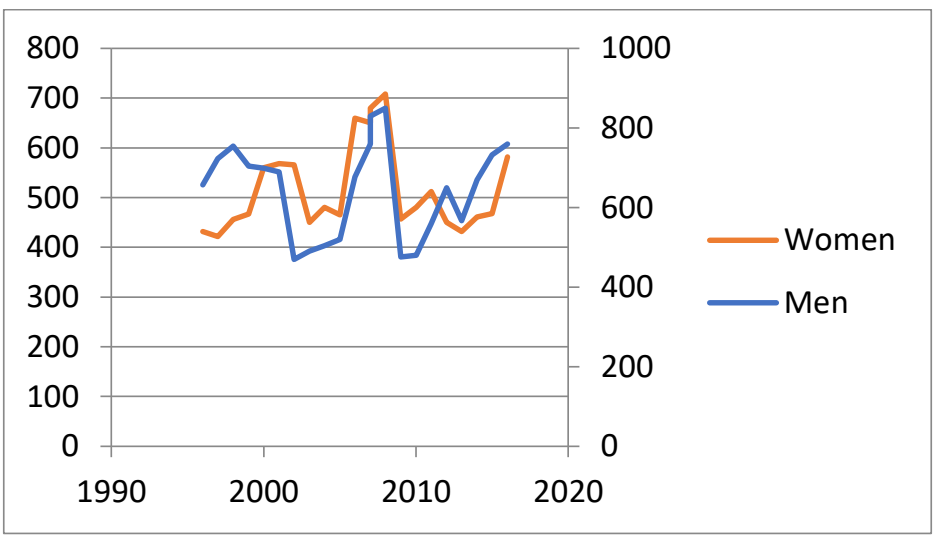

Fig. 3. Socio-Economic Factors of Women in Anja Reserve

Based on the results seen on the figure 3, it was perceived that there was an evident fluctuation of socio-economic impacts on both men and women in leadership at Anja Reserve. According to our research results, few factors may have influenced such fluctuation which may have been due to the great influence of men and their dominance over female gender in 
Anja community Reserve. Besides, it is clearly seen that in 2009 , the was a sharp decline of both gender impacting their yearly income at a low trend something that could have been caused by the non-resolvable political crisis.

Nevertheless, it is predominantly perceivable that there was a significant increase at certain time $(\mathrm{P}=0.01)$ trend, with an average of $50.0($ Std. Deviation $=2.58)$ as seen in 2009 and 2015 , while there was a decrease of $4.35 \%$ per year $(P=0.08)$ during the last fifteen years.

\subsection{Men and Women Access and Control of Resources and Markets}

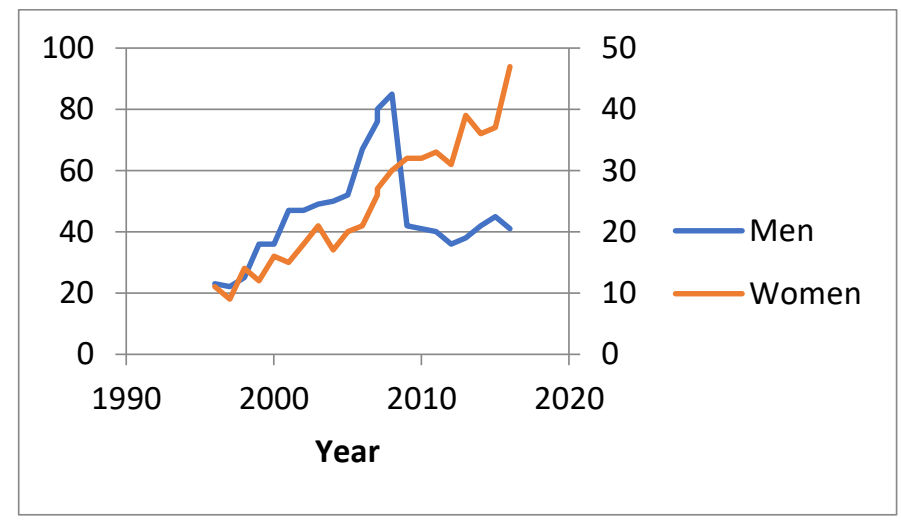

Fig. 4. Access and Control of Resources and Markets

As far as the figure 4 is concerned, it is demonstrated that there is a significant lead of male gender in having access and control of resources and markets compared to women who literally visible especially in 1996 but then started to rise in 2016 due to a recent political stability providing a promising future and empowerment for women in Anja community.

\section{Conclusion}

In this paper, few representatives in informal business in nearby village of Anja show new evidence of the huge gap on gender performance that has existed in Madagascar. There were some impacts noticed in norms and gender-differential job opportunities held by both female and male. Evidence showed that certain sectors of activity are more subject to pressure while others were influenced by the successive political crisis in 2009. To a large extent, such performance gap is due to endowment factor indicated by tremendous discrepancies between both genders since male tend to dominate at all level. [8] emphasizes gender inequality as a collection of unrelated and interlinked problems. His research discloses the gap between men and women in Pakistan.

Besides, it is undeniable to conclude that there are still many efforts needed to enhance the betterment of women's position in society despite the fact that they play a huge role in the development of the country, like the case of Anja Reserve. Also, it was perceived that the dominant role and lead of male gender would pursue its increasing trend if women are still biased or not considered at all. IWDA Report, 2014 discussed women role being underestimated in Fiji. All of these issues would undeniably require the necessity of 
governmental interference in reinforcing the laws and regulations hoping to target more female or at least an even equitable share between men and women in general.

\section{References}

[1] Christopher, "Inputs, Gender Roles or Sharing Norms? Assessing the Gender Performance Gap Among Informal Entrepreneurs in Madagascar." .

[2] C. J. Normand, F. Rakotomanana, Robilliard, and A.S., "Gender Disparities in the Malagasy Labor Market. In: J.S. Arbache, A. Kolev and E. Filipiak (eds.), Gender Disparities in Africa's Labor Market, 87-154, AFD and World Bank, Africa Development Forum." .

[3] Giddings, "Environment, economy and society: fitting them together into sustainable development.".

[4] K. Chapple, "Defining the Green Economy - A Primer on Green Economic Development.".

[5] T. 2009. S. P. P. S. M. U. P. S. Mardikanto, "Metode Penelitian dan Evaluasi Pemberdayaan Masyarakat untuk Akademisi, Praktisi, dan Peminat Pemberdayaan Masyarakat. Program Studi Penyuluhan Pembangunan/Pemberdayaan Masyarakat Pascasarjana UNS.” Surakarta.

[6] S. Notoatmodjo, Metodologi Penelitian Kesehatan. Jakarta: Rineka Cipta.

[7] A. M. Mohamed, "Women Political Participation and Decision Making in Somalia.".

[8] G. Moheyuddin, "Background, Assessment and Analysis of the Gender Issues in Pakistan.”. 